M., and Parrott, R. H.: Respiratory syncytial virus neutralizing activity in nasal secretions following natural infection. Proc. Soc. Exp. Biol. Med., 131: 658 (1969).

14. Kim, H. W., Leikin, S. L., Arrobio, J., Brandt, C. D., Chanock, R. M., and Parrott, R. H.: Coli-mediated immunity to respiratory syncytial virus induced by inactivated vaccine or by infection. Pediatr., Res., 10: 75 (1976).

15. Loda, F. A., Clyde, W. A., Jr., Glezen, W. P., Senior, R. J., Sheaffer, C. I., and Denny, F. W.: Studies on the role of viruses, bacteria and $M$. pnewmoniae as causes of lower respiratory tract infections in children. J. Pediatr., 72: 161 (1968).

16. Loda, F. A., Glezen, W. P., and Clyde, W. A., Jr.: Respiratory disease in group day care. Pediatrics, 49: 428 (1972).

17. Melntosh, K., Masters, H. E., Orr, I., Chao, R. K., and Barkin, R. M.: The immunologic response to infection with respiratory syncytial virus in infants. J. Infect. Dis., 138: 24, (1978).

18. McSharry, J. and Benzinger, R.: Concentration and purification of vesicular stomatitis virus by polyethylene glycol "precipitation." Virology, 40: 745 (1970).

19. Mills, J., Van Kirk, J. E., Wright, P. F., and Chanock, R. M.: Experimental respiratory syncytial virus infection of adults. Possible mechanismas of resistance to infection and illness. J. Immunol., 107: 123 (1971).

20. Parrott, R. H., Kim, H. W., Arrobio, J. O., Hodes, D. S., Murphy, B. R., Brandt, C. D., Camargo, E., and Chanock, R. M.: Epidemiology of respiratory syncytial virus infection in Washington, D.C. II. Infection and disease with respect to age, immunologic status, race and sex. Am. J. Epidemiol., 98: 289 (1973).

21. Schauf, V., Purcell, C., Mizen, M., and Mizen, S.: Lymphocyte transformation in response to antigens of respiratory syncytial virus. Proc. Soc. Exp. Biol. Med., 161: 564 (1979).

22. Scott, R. and Gardner, P. S.: The local antibody response to R. S. virus infection in the respiratory tract. J. Hyg. Camb., 72: 111 (1974).

23. Scott, R. and Gardner, P. S.: Respiratory syncytial virus neutralizing activity in nasopharyngeal secretions. J. Hyg. Camb., 68: 581 (1970).

24. Scott, R., Kaul, A., Scott, M., Chiba, Y., and Ogra, P. L.: Development of in vitro correlates of cell-mediated immunity to respiratory syncytial virus infection in humans. J. Infect. Dis., 137: 810 (1978).

25. Welliver, R. C., Kaul, A., and Ogra, P. L.: Cell-mediated immune response to respiratory syncytial vinus infection: relationship to the development of reactive airway disease. J. Pediatr., 94: 370 (1979).

26. Requests for reprints should be addressed to: Dr. G. W. Fernald, Department of Pediatries, University of North Carolina School of Medicine, 509 BurnettWomack Clinical Sciences Building, 229H, Chapel Hill, North Carolina, 27514 (USA).

27. This research was supported by National Heart, Lung and Blood Institute grant HL19171, National Institute of Child Health and Human Development grant HD-09139, and grants R-802233, and R-804577 from the Environmental Protection Agency.

28. Received for publication October 30, 1980.

29. Accepted for publication March 1, 1983.

\title{
Post-Hepatic Insulin Secretion in the Fetal Lamb
}

\author{
JAMES S. CRESWELL, JOHN B. SUSA, RICHARD M. COWETT, ${ }^{(16)}$ \\ DENIS G. TENENBAUM, AND WILLIAM OH(17) \\ Department of Pediatrics, Women and Infants Hospital of Rhode Island and the Section of Pediatrics, Brown \\ University Program in Medicine, Providence, Rhode Island, USA
}

\section{Summary}

Post-hematic insalin secretion was measured in six chronically catheterhed fetal lambs (fetal weight $2.8 \pm 0.3 \mathrm{~kg}$, mean \pm S.E.M.) and the results were compared with those obtained in nine prematurely delifered newborn lambs (birth weight $3.1 \pm 0.3 \mathrm{~kg}$ and postnatal age $1.3 \pm 0.2$ days). The fetal and necantal bunbin recetved either a $0.45 \%$ saline or a glucese infusion respectivehy, which resulted in a 2-fold increase in the plasma ghucose concentration. [ ${ }^{181}$ I] insulin was infused for $110 \mathrm{~min}$ to determine the rate of insulin secretion during a steady state of plasma diceose con centration. Post-hepatic insulin secretion and the metabolic elearance rate were calculated. With the 2-fold rise in plasma ghucose concentration, the post-hepatic insulin secretion rate lerressed significantly in the newborn lamb and in three out of four fetuses. The plasma insulin concentration increased significantly in the fetus (11 \pm 4.0 to $35 \pm 8 \mu \mathrm{U} / \mathrm{ml}, P<0.05)$ during ghucose stimalation as a result of decreased metabolic clearance rate of insulin $\left(10.6 \pm 1.9\right.$ to $\left.6.3 \pm 1.8 \mathrm{mi} \cdot \mathrm{kg}^{-1} \cdot \mathrm{mim}^{-1}\right)$ and an increase in posthepatic insulin secretion rate. In spite of an increase in post hepatic imsulin secretion rate, the increase in plasma insulin concentration in the newborn lamb was not significant because of lange variation $\mathrm{m}$ the values obtained. The data suggest that pancreatic beta-cells in the newborn and in the fetal lamb are equally responsive to a 2-fold increase in plasma glucose concentration.

Incremental changes in glucose concentration influence the pancreatic beta cell secretory responses in the adult (7). Using a
${ }^{[31}$ I]insulin turnover technique, we showed previously that the insulin secretion rate was similar between term and preterm lambs in the first week of life and that the response of the neonatal lamb to glucose stimulation was similar to that of adult sheep (6).

The relationship between glucose homeostasis and the rate of insulin production is also of importance in the fetus. Insulin can be demonstrated in fetal sheep pancreatic islet cells and plasma from 42 days of gestation onward. (1) Previously, inferences regarding the state of pancreatic beta-cell responsiveness to a glucose loading were based on observed changes in fetal plasma insulin levels in response to a glucose challenge. To date and to our knowledge there is no data on insulin kinetics during the fetal period.

The purpose of this study was to evaluate the rate of net insulin secretion under basal- and glucose-stimulated conditions in the preterm fetus. The data were compared with those obtained in the neonatal period from lambs of similar gestational age.

\section{MATERIALS AND METHODS}

Fetuses from six mixed breed pregnant ewes were the subjects for our fetal studies. The mean fetal weight was $2.8 \pm 0.3 \mathrm{~kg}$ with an eatimated gestational age of 130 days. Under general halothane anesthesia, indwelling polyvinyl catheters were placed in the fetal femoral artery and vein and tunneled subcutaneously to the ewe's flank. Fetal weight was estimated at the time of catheterization for calculating the dosage of $\left[{ }^{131} 1\right]$ insulin and glucose. The animals were allowed to recover at least $\mathbf{4 8} \mathrm{h}$ before the turnover study, at which time their arterial blood gas values were as follows: $\mathrm{pH} \geq$ 
7.24 , and $\mathrm{O}_{2}$ saturation $\geq 95 \%$. During the recovery period, the catheters were flushed daily with 1-2 ml of heparin $(5000 \mathrm{U} / \mathrm{ml})$ solution. All ewes were fed ad libitum and physically appeared healthy during the study.

Eight hours before the study the ewes were fasted. The studies were performed while the ewes were maintained in a sheep carrier and unrestrained. As outlined in the schematic of the protocol (Fig. 1), $0.45 \%$ saline was infused via the femoral vein 30 min after the ewe was placed in the carrier and continued for $170 \mathrm{~min}$. Blood was obtained from the fetal femoral artery for plasma glucose and insulin at $15,30,45$, and $60 \mathrm{~min}$ after saline infusion. The plasma glucose was determined within $5 \mathrm{~min}$ of sampling. When the plasma glucose values attained a steady state $( \pm 10 \%$ variation), the insulin turnover rate (secretion) was determined using the prime-constant infusion technique with a $2.5 \mu \mathrm{Ci} / \mathrm{kg}$ estimated fetal weight of $\left[{ }^{131} \mathrm{I}\right]$ insulin given as a bolus followed by $2.5 \mu \mathrm{Ci} / \mathrm{kg}$ as constant infusion over the next $110 \mathrm{~min}$. The insulin had been iodinated by the method of Freychet (8). Plasma samples were obtained at $60,70,80,90,100$, and $110 \mathrm{~min}$ after the bolus injection of iodinated insulin to determine concentrations of glucose, insulin, and $\left[{ }^{131} I\right]$ insulin radioactivity. In four of the six fetal preparations, glucose infusion was begun $2 \mathrm{~h}$ after the completion of the first kinetic analysis to approximately double the fetal blood glucose concentration. In all cases, a glucose steady state was achieved within $180 \mathrm{~min}$. Subsequently, a second insulin kinetic study was performed using the same protocol described above. The feasibility of performing two insulin kinetic studies in the same animal was confirmed when it was demonstrated in one animal that $\left[{ }^{131} I\right]$ insulin levels before beginning the second kinetic period had declined to less than $1 \%$ of steady state levels of the first turnover period. The fluid infusion rate in all studies was 0.06 $\mathrm{ml} \cdot \mathrm{kg}^{-1} \cdot \mathrm{min}^{-1}$. Arterial blood $\mathrm{pH}$ and $\mathrm{O}_{2}$ saturation, determined at designated intervals, showed that the fetus was in good acid base balance and state of oxygenation.

For the neonatal lamb study, premature delivery was achieved by fetal injection of glucocorticoid (10), which resulted in the delivery of nine well premature lambs weighing $3.1 \pm 0.3 \mathrm{~kg}$ at an estimated gestational age of approximately 130 days. They were studied at $1.3 \pm 0.2$ days. The protocol for the insulin kinetic study was similar to that of the fetal study except that the saline infusion $(n=5)$ and glucose infusion $(n=4)$ studies were done on separate groups of lambs. The plasma glucose concentration was also doubled during glucose infusion to simulate the degree of glucose stimulation for insulin secretion as was done in the fetus. The details of the study protocol for the neonatal studies have been reported previously (6), and data from six of the nine studies were included in that report.

Plasma glucose was determined by the glucose oxidase method on a glucose analyzer (Model 23A Glucose Analyzer, Yellow Springs Instrument Company, Yellow Springs, $\mathbf{O H}$ ), and insulin by the radioimmunoassay method of Hales and Randle (9). The mean $\left[{ }^{131} I\right]$ insulin specific activity was measured using immunoprecipitable insulin activity on a Packard Modumatic II Auto Gamma Scintillation Counter model 5320 (Packard Instrument
Corp., Downers Grove, IL). Post-hepatic insulin secretion was calculated during the steady state by the method of Steele (22).

Metabolic clearance rate was calculated by dividing the insulin secretion rate by the plasma insulin concentration. Statistical analysis was by paired $t$ test for comparison of studies performed in the same animal and unpaired $t$ tests for animals of heterogenous grouping.

\section{RESULTS}

Figure 2 shows the plasma glucose and insulin concentrations during the course of the study in the fetal lambs. During the saline infusion period, the plasma glucose and insulin concentrations were unchanged. During the glucose infusion period, the plasma glucose value rose 2-fold from the baseline of $18 \pm 2 \mathrm{mg} / \mathrm{dl}$ to 34 $\pm 4 \mathrm{mg} / \mathrm{dl}$ during the turnover study period $(P<0.05)$. The mean plasma insulin concentration also rose significantly from the baseline of $11 \pm 4 \mu \mathrm{U} / \mathrm{ml}$ to $35 \pm 8 \mu \mathrm{U} / \mathrm{ml}$ during the turnover period.

In the newborn lambs, as shown in Figure 3, the plasma glucose values during the baseline period were similar between the salineand the glucose-infused groups. The plasma glucose concentration remained unchanged throughout the study period in the salineinfused group whereas in the glucose-infused group the plasma glucose concentration rose significantly to twice the baseline value during glucose infusion $(81 \pm 20$ to $205 \pm 23 \mathrm{mg} / \mathrm{dl}, P<0.05)$. The plasma insulin concentrations in the saline-infused newborn lambs were unchanged during the baseline and the infusion periods. In the glucose infused group, the plasma insulin values showed large variability during the glucose infusion and no significant differences were observed between mean values when compared with the baseline period.

Data on post-hepatic insulin secretion rate in the study subjects are presented in Figure 4. Glucose infusion in the fetuses, in which a paired study was carried out, resulted in an increase in posthepatic insulin secretion in three out of four fetuses, but the mean post-hepatic insulin secretion rates with saline or glucose infusion were not different. The glucose-infused neonates evidenced a significantly higher post-hepatic insulin secretion rate in comparison to the saline-infused controls $(P<0.05)$.

The mean metabolic clearance rates after glucose infusion were not different in either the fetus or the neonate (Fig. 5). There was, however, a significant decline (by paired $t$ test) in the metabolic clearance rate in the four fetuses after glucose infusion $(P<0.05)$; nevertheless, these clearance rates are still in the range of those found during saline infusion.

\section{DISCUSSION}

The purpose of this study was to compare the post-hepatic insulin secretion rate in the fetal and neonatal lambs at a comparable gestational age. We elected to study the fetus at about 130 days of gestation because chronic fetal catheterization for metabolic study is mroe likely to be successful at this age with less attrition rate than later in the fetal period. But this approach

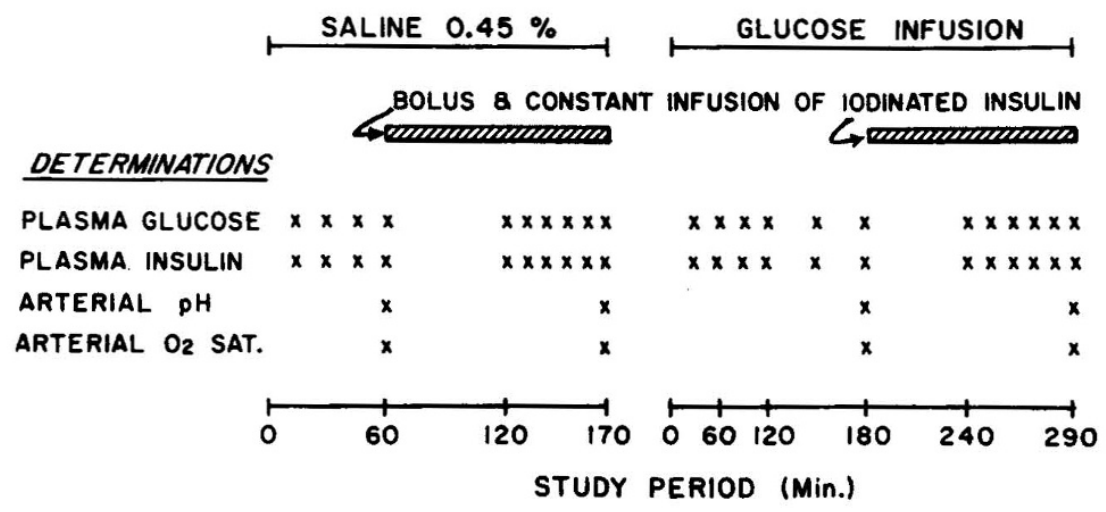

Fig. 1. Schematic presentation of the study protocol in the fetus. 


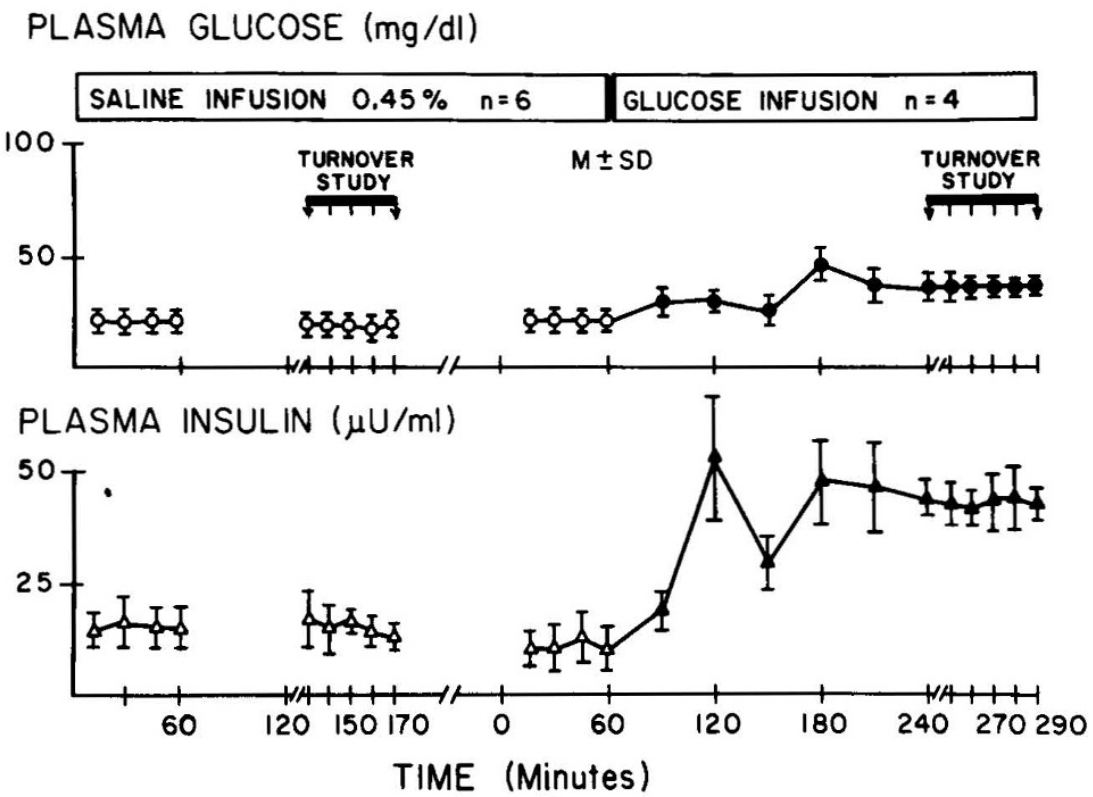

Fig. 2. Plasma glucose and insulin concentrations in the fetal lambs.

PLASMA GLUCOSE (mg/dl)
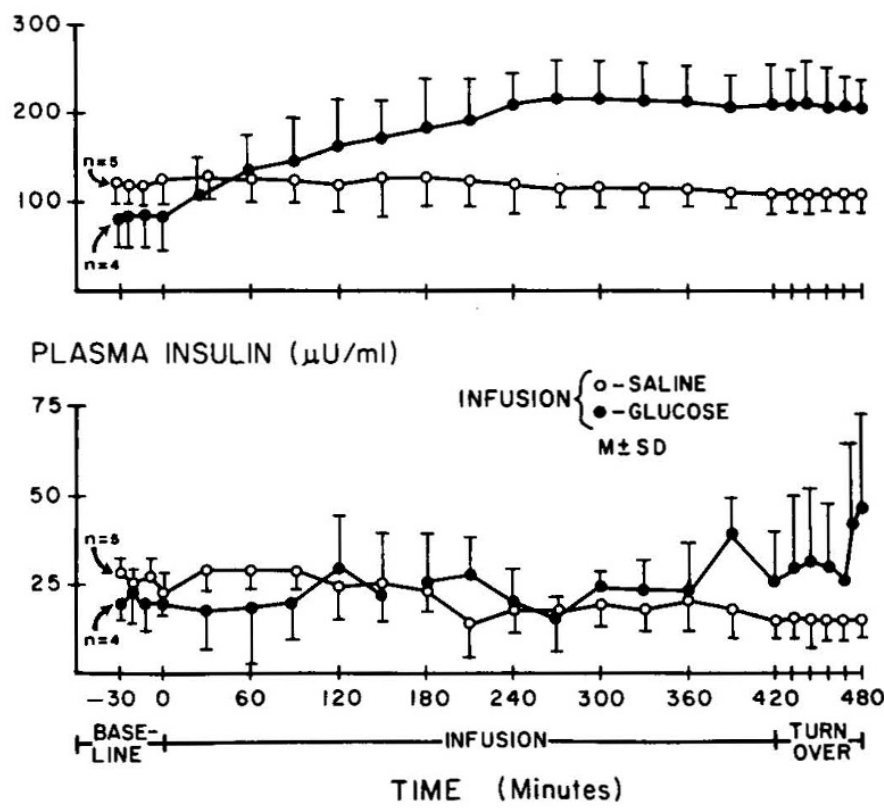

Fig. 3. Plasma glucose and insulin concentrations in the newborn lambs.

presents the difficulty of matching the neonatal lamb at comparable levels of development because delivery of newborn sheep at 130 days of gestation would invariably result in the animal having respiratory distress and poor survival. To circumvent this problem we resorted to the use of fetal glucocorticoid administration, which resulted in premature delivery of the fetus $36-38 \mathrm{~h}$ after administration as previously shown by Liggins (10). The lung maturity in these lambs was accelerated; thus, they did not have respiratory distress and generally would survive during the neonatal period. Whether the glucocorticoid administration would affect insulin secretion rate or not is unknown and this factor has to be considered in the interpretation of the current data. Because our goal was to evaluate the effect of the birth process on insulin kinetics, and a surge in corticosteroid level is one of the factors associated with onset of labor and birth (10), the use of this hormone to stabilize the premature lamb model would probably allow us to achieve the aim of our study.

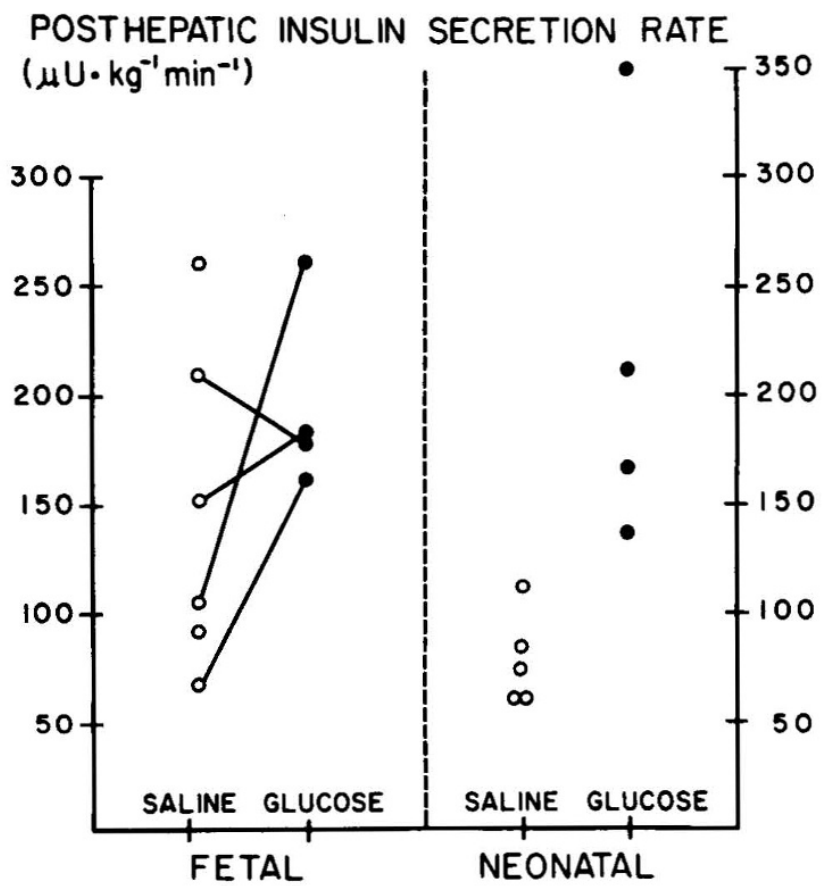

Fig. 4. Post-hepatic insulin secretion rates of the fetal and neonatal animals.

The prime and constant infusion technqiue previously reported by Steele et al. (12) has been used because interpretation of tracer kinetics is simplified during metabolic steady states in contrast to when disequilibrium states are analyzed. In addition, the use of this tracer is simplified if one assumed that the specific activity included only immunoprecipitable insulin activity. The use of isotopic tracers to derive the metabolic clearance rate requires the assumption that the removal of iodinated insulin from the plasma pool is not subject to an isotope effect. Although we cannot totally exclude the possibility that native unlabeled and iodinated insulin are degraded at different rates, we consider it unlikely. The iodination method used in this study results in the production of monoiodoinsulin with bioactivity identical to that of native insulin (8). This would imply that the removal of monoiodoinsulin from the plasma pool proceeds via the same mechanism and rate as native unlabeled insulin. 
INSULIN

METABOLIC CLEARANCE RATE $\left(\mathrm{ml} \cdot \mathrm{kg}^{-1} \mathrm{~min}^{-1}\right)$

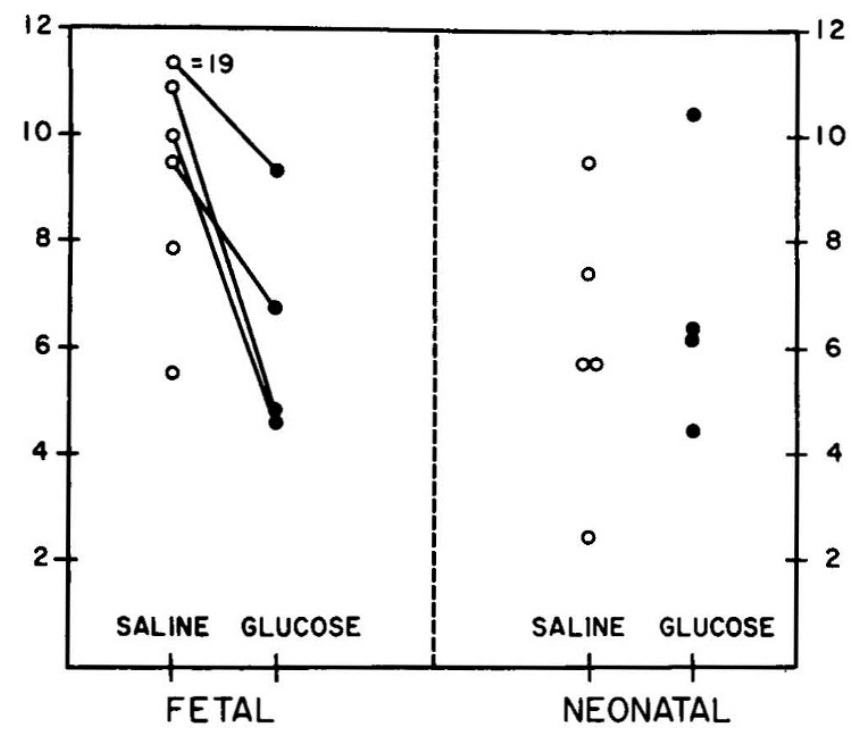

Fig. 5. Metabolic clearance rates of the fetal and neonatal animals.

The term post-hepatic insulin secretory rate has been used to reflect our inability to measure absolute insulin secretion from the pancreas. This term describes the "net insulin secretion," which reflects hepatic extraction of insulin from the portal circulation. The peripheral plasma insulin concentration used in the calculation reflected total pancreatic insulin secretion minus the combined degradation of insulin by liver, muscle, and kidney.

Our study design was constructed in such a way that both in the fetal and neonatal subjects, the increment in plasma glucose concentration after the glucose infusion was approximately twice the concentration of the baseline values. The similarity in the increment in glucose concentration allowed for the interpretation of the insulin secretion rate between the fetal and neonatal animals.

In the newborn lamb, the rise in plasma glucose resulted in the significant increase in the post-hepatic insulin secretion rate whereas the metabolic clearance rate for insulin was unchanged, which would be expected to result in a significant increase in the plasma insulin concentration. Our data did show an increase in plasma insulin concentration. Unfortunately, the large variation and small number of observations resulted in the differences not being statistically significant.

In the fetus, under comparable glucose stimulation (2-fold increase), insulin secretion rate was also increased in three out of four experiments. The metabolic clearance rate of insulin in the fetus was reduced significantly after glucose stimulation. The increase in the plasma insulin levels in the fetus is probably due to its increased secretion and reduced clearance. In the intrauterine state, the placenta plays an important role in the degradation of insulin. Whether glucose stimulates placental degradation and, hence, insulin clearance is not known and deserves further investigation.

Previous investigations by others on the effect of glucose infusion and insulin metabolism in the perinatal period have shown a marked variability in results $(2,5,11,14)$. This is probably due to the differences in methodology. For instance, Willes et al. (14) studied the response to fetal intravenous glucose challenge in the chronic ovine fetus from 100-146 days gestation. They demonstrated no elevation in plasma insulin concentration after bolus injection of either an $0.5 \mathrm{~g}$ or $1.0 \mathrm{~g}$ glucose $/ \mathrm{kg}$ fetal body weight. These data are in contrast to our results in newborn lambs and adult sheep, probably because of the difference in the method of glucose administration i.e., bolus versus continuous infusion, the latter achieving a steady state. Alexander et al. (2) employed a similar fetal preparation to study insulin response to bolus glucose injection. The authors, using a slightly higher glucose load (0.8$1.4 \mathrm{~g}$ glucose $/ \mathrm{kg}$ fetal body weight) in three animals $(118,122$, and 138 days gestation) found insulin elevations in response to glucose loading in seven out of eight injections. Whether the difference in the finding of Willes $e t a l$. and those of Alexander $e t$ $a l$. is due to dose differences is unclear. Continuous maternal glucose infusion sufficient to raise the fetal plasma glucose concentration from $19.4 \mathrm{mg} / \mathrm{dl}$ to $160 \mathrm{mg} / \mathrm{dl}$ in $60 \mathrm{~min}$ was found by Bassett and Thorburn (4) to be associated with a significant rise in fetal plasma insulin concentrations from $8.8 \mu \mathrm{U} / \mathrm{ml}$ to $35 \mu \mathrm{U} /$ $\mathrm{ml}$. This response was seen in all six of the fetuses studied, which ranged from 104 to 136 days gestation. Subsequently, Bassett and Madill (3) showed that greatly prolonged glucose infusion of both 40 and $60 \mathrm{mg}$ of glucose/min into fetal lambs close to term resulted in significant increases in fetal plasma glucose and insulin concentrations, which were observed within $1 \mathrm{~h}$ and sustained over the 5-day period. These plasma insulin responses to glucose in fetal sheep are similar to ours. More recently, Phillips and coworkers (11) confirmed these observations in fetal sheep. In addition, using fetal rats, he confirmed the report by Blazquez $e t$ al. (5), which demonstrated a diminished early response to glucose stimulation, but a significant late response of fetal insulin secretion to a glucose stimulus. Also, Blazquez et al. have observed that insulin-response curves of fetal lambs are similar to maternal insulin-response curves, suggesting a similar sensitivity to glucose stimulus between fetal and maternal sheep. We have observed large variation in post-hepatic insulin secretion rates in the fetal and neonatal lambs. The source of this variability is difficult to identify; however, this variability is not restricted to the fetal or neonatal lamb. In adult man Stern et al. (13) have found irreversible loss rates of insulin from plasma in fasting man to range from $1200-10,455 \mu \mathrm{U} / \mathrm{min}$. In adults receiving glucose infusions that resulted in plasma glucose concentrations approximately twice fasting levels the rates of insulin secretion ranged from 6278$37,818 \mu \mathrm{U} / \mathrm{min}$. They concluded that widely different amounts of insulin are released by different subjects in order to maintain similar steady-state plasma glucose concentrations.

Our studies of insulin turnover show that post-hepatic insulin secretion rates in response to glucose stimulation in the neonatal and fetal lamb of comparable gestational age are similar. This work extends our previous studies and suggests a similar insulin secretion in response to glucose stimulation in fetal, preterm, term, and adult sheep. We conclude that the fetal sheep pancreas during the latter part of gestation is physiologically mature and capable of responding appropriately by increasing insulin secretion to the rapid increases of plasma glucose concentration associated with the transition from intrauterine to extrauterine life.

\section{REFERENCES AND NOTES}

1. Alexander, D. P., Britton, H. G., Cohen; N. M., Nixon, D. A., and Parker, R. A. Insulin concentrations in the foetal plasma and foetal fluids of the sheep. $J$. Endocrinol., 40: 389 (1968).

2. Alexander, D. P., Britton, H. G., Mashiter, K., Nixon, D. A., and Smith, F. G.: The response of foetal sheep in utero to intravenous glucose. Biol. Neonate, 15: 361 (1970).

3. Bassett, J. M. and Madill, D.: Influence of prolonged glucose infusions on plasma insulin and growth hormone concentrations of foetal lambs. J. Endocrinol., 62: 299 (1974)

4. Bassett, J. M. and Thorburn, G. D.: The regulation of insulin secretion by the ovine foetus in utero. J.Endocrinol., 50: 59 (1971).

5. Blazquez, E., Lipshaw, L. A., Blazquez, M., and Foa, P. P.: The synthesis and release of insulin in fetal, nursing, and young adult rats: studies in vivo and in vitro. Pediatr, Res., 9: 17 (1975).

6. Cowett, R. M., Susa, J. B., Warburton, D., Stonestreet, B., Schwartz, R., and Oh, W.: Endogenous post-hepatic insulin secretion and metabolic clearance rates in the newborn lamb. Pediatr. Res., 14: 1391 (1980).

7. Field, J. B.: Extraction of insulin by the liver. Ann. Rev. Med., 24: 309 (1973).

8. Freychet, P., Roth J., and Neville, D. M.: Monoido insulin: demonstration of its biological activity and binding to fat cells and liver membranes. Biochem. Biophys. Res. Comm., 43: 400 (1976).

9. Hales, C. N. and Randle, P. H.: Immunoassay of insulin with insulin antibody precipitates. Biochem. J., 88: 137 (1963). 
10. Liggins, M.: Premature delivery of foetal lambs infused with glucocorticoids. J.Endocrinology, 45: 515 (1969).

11. Phillips, A. F., Carson, B. S., Meschia, G. and Battaglia, F. C.: Insulin secretion in fetal and newborn sheep. Am. J. Physiol., 235: E467 (1978).

12. Steele, R., Wall, J. E., DeBodo, R. C., and Altzuler, N.: Measurement of size and turnover rate of body glucose pool by the isotopic dilution method. Am. J. Physiol., 187: 15 (1956).

13. Stern, M. P., Farguhar, J. W., Silvers, A., and Reaven, G. M.: Insulin delivery rate into plasma in normal and diabetic subjects. J. Clin. Invest., 47: 1947 (1968).

14. Willes, R. F., Boda, J. M., and Manns, J. G.: Insulin secretion by the ovine fetus in utero. Endocrinology, 84: 520 (1969).
15. We acknowledge the technical assistance of Ms. Betty Kelley and Mr. William Macomber and the secretarial assistance of Mrs. Lea Gold and Ms. Donna Perry.

16. Dr. Cowett is recipient of an RCDA, KO-4 HD-00308, NICHHD, Bethesda, MD.

17. Requests for reprints should be addressed to: Dr. William OH, 50 Maude Street, Providence, RI 02908.

18. This research was supported in part by Major Research Programs (HD 11343) of the National Institute of Child Health and Human Development, Bethesda, MD

19. Received for publication August 10, 1982.

20. Accepted for publication February 14, 1983.

\title{
Intrarenal Distribution of Renin in the Developing Rabbit
}

\author{
ALFRED DRUKKER, ${ }^{(37)}$ VICKI S. DONOSO, MICHAEL A. LINSHAW, AND MICHAEL D. BAILIE ${ }^{(38)}$ \\ Department of Pediatrics and Kansas University Kidney and Urology Research Center, The University of Kansas \\ College of Health Sciences and Hospital, Kansas City, Kansas, USA
}

\section{Summary}

The purpose of this study was to evaluate the intrarenal distribution of renin in individual glomerull during development in the rabbit. Superficial cortical and juxtamedullary glomeruli were obtained from animals at 1,2 , and 4 wk of age and from adults to determine renin concentration. In addition, kidney weight, total renal renin content, plasma renin concentration, and plasma angiotensin I concentration were also measured during this time period. Superficial cortical glomerular renin concentration at 1 wk of age averaged $7.7 \pm 1.6$ (S.E.M.) pg/h whereas juxtamedullary glomerular renin concentration was $4.5 \pm 1.8 \mathrm{pg} / \mathrm{h}$. There was no difference in concentration between the superficial and deep glomeruli at this age. At 2 wk of age, however, superficial glomerular content had increased significantly to $143.8 \pm 2.94 \mathrm{pg} / \mathrm{h}$ whereas the juxtamedullary concentration remained unchanged $(7.9 \pm 1.6$ $\mathrm{pg} / \mathrm{h}$ ). The concentration in the superficial nephrons continued to increase with age. At 4 wk, superficial renin content was $224.6 \pm$ 27.2 whereas the deep nephrons did not change $(16.0 \pm 7.5 \mathrm{pg} / \mathrm{h})$. Adult animals demonstrated a further increase to $842.7 \pm 15.1 \mathrm{pg} /$ $h$ in the superficial nephrons whereas the deep nephrons continued to remain low $(15.9 \pm 4.7 \mathrm{pg} / \mathrm{h})$.

The results of this study demonstrate that after the first week of life there was significantly more renin activity in glomerulf in the outer cortex than in the juxtamedullary cortex. Total renal renin concentration increased with age and showed a significant positive correlation with the concomitant increase in kidney weight. But renal renin content increased more than kidney weight between 1-2 wk of age.

\section{Abbreviations}

\section{AI, angiotensin I}

GRC, glomerular renin concentration

PAI, plasma angiotensin I

PRC, plasma renin concentration

RAS, renin-angiotensin system

RRC, renal renin content
The renin-angiotensin-aldosterone axis is active at birth and responds qualitatively though not quantitatively, to stimuli in a manner similar to that observed at a later age $(8,12,13,17,21,24$, 30). Relatively few data are available regarding the physiologic role of the RAS in infancy and childhood. The RAS has been implicated in the regulation of systemic and renal hemodynamics, glomerular filtration rate, glomerulotubular balance, and sodium homeostasis both in the adult animal and during development (6, $19,23,31)$. In the adult animal, the distribution of renin in the renal cortex shows a characteristic pattern. The concentration of renin is greatest in outer cortical glomeruli and far less in juxtamedullary nephrons $(3,7)$. In the immediate postnatal period, the newborn kidney undergoes rapid morphologic and functional changes; therefore, we reason that developmental change in the intrarenal distribution of renin, if present, may be important in modulating adaptive changes in neonatal renal function. The purpose of this study was to evaluate the intrarenal distribution of renin in individual glomeruli during development in the rabbit. In addition to measurement of glomerular renin content in single superficial cortical and juxtamedullary glomeruli, plasma renin concentration, plasma angiotensin I concentration, and total renin renal renin concentration were determined during development.

\section{MATERIALS AND METHODS}

Group I. Determination of PRC, PAI concentration and total $\boldsymbol{R} \boldsymbol{R C}$. These experiments were carried out in rabbits of the following ages: 1 day $(n=5), 3$ days $(n=5), 1$ and 2 wk $(n=4), 1$ month $(n=5)$, and adult $(n=5)$. The youngest animals were killed by decapitation; blood was collected directly into polystyrene tubes containing disodium ethylenediamenetetraacetic acid (EDTA); and the right kidney was excised. In the adult animal, blood was drawn from an ear vein while the animals were restrained in a sling and then nephrectomy was performed after anesthesia was induced with intravenous pentobarbital sodium.

Group II. Determination of renin content of single glomeruli. These experiments were performed on suckling newborn rabbits of both sexes and on adult male rabbits. Four animals were 